\title{
Realisering av meningsfulle personlige mål: en ny måte å forebygge selvmord på
}

\author{
Ved Sylvie Lapierre, Micheline Dubé, Léandre Bouffard og Michel Alain
}

\begin{abstract}
Mye av den empiriske selvmordsforskningen er konsentrert om å identifisere risikofaktorer (De Leo et al., 2004), noe som har ført til utvikling av forskjellige forebyggings- og intervensjonsstrategier. Usikkerheten knyttet til effekten av disse strategiene (Hawton et al., 1998; Hepp et al., 2004) førte til at De Leo (2002) mente det kunne være fruktbart å fokusere på beskyttelsesfaktorer. Siden håp og mening med livet er to beskyttelsesfaktorer mot selvmord (Malone et al., 2000), ville vi undersøke om et program med fokus på realisering av personlige mål kunne hjelpe suicidale deltakere til bedre psykisk velvære.
\end{abstract}

\section{Mål og psykisk velvære}

Intervensjonsprogrammet som beskrives i denne artikkelen, ble ikke utviklet med tanke på selvmordsforebygging. Det ble utviklet som en strategi for å fremme psykisk helse, der man legger vekt på å utvikle holdninger og ferdigheter som hjelper deltakerne til å realisere personlige prosjekter som gir livet deres mening (Watson \& Tharp, 1997). Det bygger på et sterkt teoretisk og empirisk fundament som knytter tilstedeværelse og oppnåelse av personlige mål til psykisk velvære (Dubé et al., under trykking; Emmons, 2003). Det virker som om evnen til å planlegge og realisere relevante indre mål fører til lykke og psykisk velvære (Csikszentmihalyi, 1997; Schmuck \& Sheldon, 2001). Ifølge Snyder \& Rand (2004) vil mennesker som har håp, ta ansvar for sitt eget velvære, tro at de kan bedre sin egen situasjon og aktivt gå inn for å løse problemene sine. På den annen side la Brandtstädter og Rothermund (2002) merke til at det å miste kontroll over realisering av viktige mål og manglende evne til å frigjøre seg fra disse målene er to risikofaktorer for depresjon.

\section{Intervensjonsprogram med vekt på personlige mål}

Formålet med intervensjonsprogrammet er å hjelpe deltakerne til å uttrykke, planlegge, arbeide for og nå meningsfulle, konkrete og realistiske personlige mål. Programmet besto av 11 ukentlige m $\varnothing$ ter à to timer i små grupper med 7-10 deltakere. Hver gruppe ble ledet av en pensjonist og en mastergradsstudent $\mathrm{i}$ psykologi som var blitt lært opp i gruppelederrollen. Opplegget bygger på kognitiv atferdstilnærming med følgende målsetting: $\varnothing$ ke deltakernes evne til å identifisere og endre irrasjonelle og negative tanker som hindrer måloppnåelsesprosessen, fremme kognitive faktorer som gjør deltakerne bedre i stand til å regulere handlingene sine, og forbedre deltakernes evne til å se alternative måter å oppnå et mål på.

Programmet starter med to forberedende møter (møte 1 og 2): I det første møtet stimulerer en hyggelig sosial aktivitet til gruppesamh $\varnothing$ righet og samarbeid. Det andre møtet gir deltakerne mulighet til å snakke om det tapet de har opplevd. I vårt aktuelle tilfelle dreide samtalen seg om tap av arbeid på grunn av pensjonering. Dette møtet er av avgjørende betydning fordi det hjelper gruppemedlemmene til å sette ord på følelsene om denne vanskelige endringen i livssituasjonen, og til å innse at andre føler det på samme måte. Etter det andre møtet begynner deltakerne å arbeide med målene sine. På dette stadiet skal deltakerne gjennom tre hovedfaser: sette seg mål, planlegge hvordan målet kan nås og arbeide for å nå målet. Til slutt evalueres resultatet.

I første fase hvor deltakerne skal sette seg mål, avholdes tre møter (møte 3, 4 og 5). I møte 3 skal deltakerne lage en liste over sine forhåpninger og interesser ved å skrive 23 setninger som begynner med: "Jeg håper...”, "Jeg ønsker...", "Jeg planlegger...”. I dette møtet skal deltakerne også identifisere negative tanker som kan hindre dem i å nå målet. For eksempel tror mange pensjonister at de er for gamle for enkelte prosjekter. Andre tror at de mangler evnene som trengs for å realisere målet sitt, mens noen er redde for at andre mennesker vil mislike ambisjonene deres. Slike negative tanker må identifiseres og tas tak i gjennom hele prosessen. I løpet av møte 4 velger deltakerne ut fem mål med høy prioritet og evaluerer dem fra forskjellige sider (innsats, stress, glede, vanskelighetsgrad, ressurser, konflikter, kontroll osv.). Ved hjelp av denne $\varnothing$ velsen og gruppedisku- sjonen oppdager deltakerne hva som kjennetegner målene deres. Noen finner for eksempel ut at de velger seg mål for å gjøre andre til lags eller ut fra pliktfølelse, men sjelden for sin egen forn $\varnothing$ yelses skyld. Til slutt, i møte 5, velger deltakerne ut ett mål som de overfører til en målatferd, beskrevet i konkrete og presise termer for å gjøre målet lettere å realisere. For eksempel kan målet: "forbedre forholdet til ektefellen min" defineres som to målatferder slik: "møtes til en intim middag en gang i uken" eller "gjøre noe sammen i helgen" som utgjør to forskjellige og spesifikke mål å nå. På slutten av første fase der deltakerne skal sette seg mål, forplikter hver deltaker seg til å prøve å fullføre prosjektet sitt.

I løpet av planleggingsfasen (møte 6 og 7) velger deltakerne ut effektive metoder og konkrete handlinger for å nå målet. De setter av tid, prøver å forutse hvilke hindringer de kan st $\varnothing$ te på og hvilke strategier de kan bruke for å overkomme disse hindringene, og de finner ressurser som kan hjelpe dem til å nå målet.

I den fasen hvor deltakerne arbeider for å nå målet (møte 8, 9 og10), setter de handlingsplanen sin ut i livet, evaluerer sin egen innsats og fremgang, identifiserer tanker, følelser og atferd som gjør det vanskeligere eller lettere å nå målet, og foretar de nødvendige justeringer. Gjennom hele programmet deler deltakerne erfaringene sine med hverandre og gir og får forslag og støtte til å møte de utfordringene som de blir stilt overfor. Til slutt, i møte 11, evaluerer de hva de har oppnådd og resultatet av læringsprosessen.

\section{Metode}

Nylig evaluerte Dubé, et al. (under trykking) intervensjonsprogrammets virkning på psykisk velvære blant 294 førtidspensjonister (i alderen 50 til 65 år). 
De positive resultatene inspirerte oss til å finne ut om dette programmet også kunne ha verdi i selvmordsforebyggende arbeid. Som tidligere nevnt, var ikke selvmord tema for denne forskningen. Det var imidlertid ett spørsmål som gjorde det mulig å identifisere deltakere med selvmordstanker: "Tenkte du noen gang i løpet av den siste uken på å gjøre slutt på livet? Tjueen (21) personer (gjennomsnittsalder 56,7 år) svarte “ja” ved pretest: 10 (5 menn og 5 kvinner) i eksperimentgruppen og 11 (6 menn og 5 kvinner) i kontrollgruppen. Det var ingen signifikant forskjell mellom gruppene når det gjaldt sosiodemografisk profil.

Velvære ble evaluert ved hjelp av følgende instrumenter: Retirement Experience Assessment Scale (Lapierre \& Bouffard, 2001a), Short Happiness and Affect

Research Protocol (Stones et al., 1996), Serenity Scale (Roberts \& Aspy, 1993), Tenacious Goal Pursuit and Flexible Goal Adjustment scales (Brandtstädter \& Renner, 1990), Psychological Distress Index (Préville, et al., 1995) og Geriatric

Depression Scale (Yesavage, et al., 1983). Den sistnevnte målemetoden brukes som et screening-instrument, ikke som diagnoseredskap. To instrumenter ble dess- uten brukt til å avgjøre om programmet hadde noen virkning på målrelaterte variabler: Goal Achievement Process Questionnaire (Lapierre \& Bouffard, 2001b), som måler en persons evne til å sette seg, planlegge og arbeide for å nå personlige mål, og State Hope Scale (Snyder et al., 1996), som evaluerer besluttsomhet og evne til å tenke ut alternative veier til målet. Deltakerne i eksperimentgruppen ble invitert til å delta i et arbeidsseminar som skulle hjelpe dem til å mestre pensjonisttilværelsen og bedre livskvaliteten deres, mens kontrollgruppen ble rekruttert i en egen unders $\varnothing$ kelse som gjaldt tilpasning til pensjonisttilværelsen. Deltakerne i begge gruppene svarte på alle spørreskjemaene i de samme måleperiodene: pretest, posttest (ved slutten av programmet) og oppfølging seks måneder senere.

\section{Resultater}

Innledende analyser viste ingen signifikant forskjell mellom gruppene for noen av variablene ved pretest. Variansanalyse med repeterte målinger, 2 (grupper) X 3 (tidspunkt) indikerte at deltakerne $\mathrm{i}$ eksperimentgruppen hadde betydelig st $\varnothing$ rre fremgang over tid enn deltakerne i kontrollgruppen, både når det gjaldt måloppnåelse (også underskalaene for å sette seg mål og arbeide for å nå dem), håp (også underskalaene for besluttsomhet og evne til å tenke alternativt), opplevelse av pensjonisttilværelsen, sinnsro, fleksibilitet, depresjon og psykisk smerte. Se tabell 1 nedenfor.

\section{Diskusjon}

Litteratur om faktorer som beskytter mot selvmord (Malone et al., 2000), fikk oss til å tro at det kunne være mulig å forbedre den psykiske helsen til mennesker med selvmordstanker ved å hjelpe dem med å realisere personlige prosjekter som gir livet deres mening. Resultatene i den foreliggende studien ble oppnådd med et lite delutvalg $(\mathrm{n}=21)$ av deltakere som hadde gitt uttrykk for selvmordstanker. De var tatt ut fra et større utvalg av 294 personer som nettopp hadde gått av med pensjon (Dubé et al., under trykking). Sammenligninger mellom eksperimentgruppe og kontrollgruppe, med repeterte målinger (ANOVA), viste at de som deltok i programmet hadde en signifikant $\varnothing \mathrm{kning}$ i velvære sammenliknet med dem som ikke deltok i programmet.

Tabell 1 Realisering av meningsfulle personlige mål: intervensjonsprogram.

Resultater for intervensjonsgruppen og kontrollgruppen $(\mathrm{N}=21)$

\begin{tabular}{|c|c|c|c|c|c|c|c|c|c|c|c|c|c|c|}
\hline & \multicolumn{6}{|c|}{ Eksperimentgruppen $(n=10)$} & \multicolumn{6}{|c|}{ Kontrollgruppen ( $n=11)$} & \multirow{2}{*}{\multicolumn{2}{|c|}{$\begin{array}{l}\text { Varians- } \\
\text { analyse } \\
\text { Gruppe x } \\
\text { tidspunkt }\end{array}$}} \\
\hline & \multicolumn{2}{|c|}{ Pretest } & \multicolumn{2}{|c|}{ Posttest } & \multicolumn{2}{|c|}{ Oppfølging } & \multicolumn{2}{|c|}{ Pretest } & \multicolumn{2}{|c|}{ Posttest } & \multicolumn{2}{|c|}{ Oppfølging } & & \\
\hline & M & $\mathrm{SD}$ & M & $\mathrm{SD}$ & M & $\mathrm{SD}$ & M & $\mathrm{SD}$ & M & $\mathrm{SD}$ & M & $\mathrm{SD}$ & F & $\begin{array}{c}\mathrm{p}- \\
\text { verdi }\end{array}$ \\
\hline Måloppnåelse/7 & 3.84 & 1.19 & 5.14 & 1.02 & 4.97 & .95 & 4.60 & 1.18 & 4.38 & 1.05 & 4.55 & 1.23 & 5.93 & .006 \\
\hline Håp /4 & 2.66 & .75 & 3.15 & .42 & 3.22 & .39 & 2.90 & .77 & 2.86 & .53 & 2.77 & .51 & 4.01 & .027 \\
\hline $\begin{array}{l}\text { Opplevelse av } \\
\text { pensjonisttilværelsen/7 }\end{array}$ & 4.84 & 1.37 & 5.63 & 1.31 & 5.84 & .83 & 4.62 & 1.74 & 4.49 & 1.67 & 4.42 & 1.48 & 4.46 & .018 \\
\hline Lykke /1 & .01 & .42 & .28 & .38 & .25 & .34 & .10 & .30 & -.02 & .36 & .16 & .35 & 2.85 & .070 \\
\hline Sinnsro $/ 5$ & 2.81 & .70 & 3.40 & .75 & 3.45 & .77 & 3.25 & .63 & 3.15 & .64 & 3.24 & .51 & 4.16 & .023 \\
\hline Fleksibilitet /4 & 2.19 & .58 & 2.41 & .74 & 2.54 & .70 & 2.52 & .51 & 2.41 & .38 & 2.42 & .47 & 3.69 & .034 \\
\hline Utholdenhet /4 & 2.33 & .46 & 2.42 & .47 & 2.47 & .33 & 2.33 & .51 & 2.31 & .39 & 2.20 & .67 & .93 & .403 \\
\hline Depresjon /1 & .56 & .33 & .32 & .34 & .26 & .30 & .40 & .26 & .42 & .27 & .38 & .23 & 5.17 & .010 \\
\hline Psykisk smerte /4 & 2.35 & .80 & 1.82 & .58 & 1.72 & .52 & 2.09 & .59 & 2.03 & .59 & 1.96 & .37 & 3.31 & .047 \\
\hline
\end{tabular}

Tallet etter hver variabel indikerer det høyeste tallet på skalaen. Laveste tall på hver skala er 1, bortsett fra Lykke og Depresjon der 0 er usant og 1 er sant. 
For det første virker det som programmet bedret deltakernes evne til å fullføre prosjekter (variabelen måloppnåelse), særlig ved å hjelpe dem med å sette seg realistiske og konkrete mål (underskalaen for å sette seg mål) og ved å lære dem å overvinne hindringer som oppstår mens de arbeider med å nå målet (underskalaen for å arbeide for å nå målet). De fikk også større håp; deltakerne satte sine planer ut i handling med st $\varnothing$ rre besluttsomhet og utviklet evnen til å finne alternative måter å oppnå målene sine på. Dette er svært interessant siden suicidale personer er kjennetegnet av en følelse av hjelpeløshet og håpløshet, og av at de har vanskelig for å se for seg og evaluere alternative løsninger (Freeman \& Reinecke, 1993). For det andre synes programmet å ha forbedret det psykiske velværet til disse suicidale pensjonistene, som fikk et mer positivt syn på pensjonisttilværelsen. At de skårer signifikant høyere på fleksibilitet og sinnsro er et viktig resultat. Det viser at deltakerne i målprogrammet, i motsetning til deltakerne i kontrollgruppen, lærte å endre eller gi avkall på uoppnåelige mål, tilpasse målene sine ut fra situasjonsbetingede hindringer, og vende seg mot nye, mer realistiske og tilfredsstillende prosjekter. De fikk også st $\varnothing$ rre sinnsro, noe som indikerer at de aksepterte ting som ikke kan endres, utviklet tillit til livet og fremtiden og fant indre fred. Disse resultatene er lovende når det gjelder å forebygge selvmord siden kognitiv rigiditet og forvrengning samt negative tanker er vanlige blant suicidale personer (Freeman \& Reinecke, 1993).

For det tredje oppmuntrer den betydelige nedgangen i nivået på depresjon og psykisk smerte til å fortsette forskningen på beskyttende faktorer, slik som utvikling av meningsfulle personlige prosjekter. Det er verdt å merke seg at de positive resultatene av programmet varte ved seks måneder senere. Og av de 10 suicidale deltakerne som svarte at de tenkte på å gjøre slutt på livet før de startet programmet, svarte 8 "nei" ved oppfølging, mens bare 4 av de 11 deltakerne i kontrollgruppen gav et negativt svar.

\section{Videre studier}

Verdien av gruppest $\varnothing$ tte ble ikke evaluert i studien. Det var imidlertid ikke uvanlig at noen av gruppene i den store studien fortsatte å møtes etter at forskningsperioden var over. Vi vet ikke om dette også gjaldt for de suicidale deltakerne. Virkningen av det sosiale aspektet i programmet på forskjellige variabler som for eksempel ensomhet og sosial st $\varnothing t t e$ kan gjerne evalueres i en fremtidig studie.

Programmet synes å være nyttig for alle som trenger å forandre prioriteringsrekkefølgen for sine personlige mål, slik man ofte må som følge av tap eller endring i livet (tap av arbeid, helse, ektefelle, eller ved slutten av en livsfase). For suicidale personer må det høyt prioriterte $\varnothing$ nsket om å gjøre selvmord for å få en slutt på smerte og lidelse, erstattes av nye prioriteringer. På den måten kan nye livsmål vokse frem og tilfredsstille fundamentale psykologiske behov (Michel \& Valach, 2001). Den positive virkningen programmet hadde på suicidale deltakere, var overraskende siden det ikke var beregnet for denne gruppen. Det ville derfor være interessant å finne ut om det er mulig å tilrettelegge programmet for et st $\varnothing$ rre utvalg av suicidale personer som har opplevd et stort tap. De foreliggende resultatene innebærer ikke at programmet bør gjennomf $\varnothing$ res med personer som har en historie med psykisk sykdom eller selvmordsatferd, men med mennesker som opplever en enkelt episode med depresjon ledsaget av suicidale tanker. Nye studier bør evaluere mer presist deltakernes suicidale tanker og atferd, depresjonens nivå og type, mening i livet, og grunner til å leve. Forskning på disse variablene kan føre til en bedre forståelse av hvilken rolle beskyttelsesfaktorer spiller i forebygging av selvmord. Vi konkluderer med at det synes som denne typen intervensjon var til signifikant nytte for deltakerne og kan være en lovende og nyskapende tilnærming til forebygging av selvmord. Det vil imidlertid være nødvendig med nye studier for å kunne fastslå at denne typen program kan hindre selvmord, men programmet synes å underbygge og oppmuntre til initiativer som skaper forebyggings- eller intervensjonsprogrammer basert på beskyttelsesfaktorer. Det er nytt håp for selvmordsforskningen.

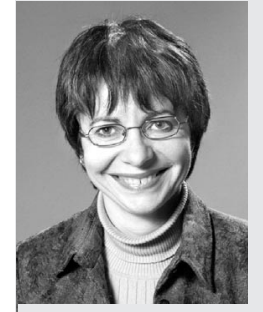

Sylvie Lapierre er professor ved Department of psychology ved Universitetet i Québec i Trois-Rivières og direkt $\varnothing$ for forskningslaboratoriet i gerontologi. Hennes hovedinteresse ligger innenfor området håp og håpløshet hos pensjonister og eldre voksne, og i studiet av optimal aldring.

Micheline Dubé og Michel Alain er professorer ved Department of Psychology ved Universitetet i Québec i Trois-Rivières.

Leandre Bouffard er førsteamanuensis samme sted.

Artikkelen er oversatt av Kari-Helene Hestvik.

\section{Referanser:}

Brandtstädter, J., \& Renner, G. (1990). Tenacious goal poursuit and flexible goal adjustment. Psychology and Aging, 5(1), 58-67.

Brandtstädter, J., \& Rothermund, K. (2002). The life-course dynamics of goal pursuit and goal adjustment : A two-process framework. Developmental Review, 22(1), 117-150.

Csikszentmihalyi, M. (1997). Finding flow:

The psychology of engagement in everyday life. New York : Basic Books.

De Leo, D. (2002). Why are we not getting any closer to preventing suicide? British Journal of Psychiatry, 181, 372-374.

De Leo, D., Bille-Brahe, U., Kerkhof, A., \& Schmidtke, A. (Eds.) (2004). Suicidal behavior. Theories and research findings. Cambridge (MA): Hogrefe \& Huber.

Dubé, M., Lapierre, S., Bouffard, L., \& Alain, M. (Under publ.). Impact of a personal goal management program on the subjective well-being of young retirees. European Review of Applied Psychology.

Emmons, R.A. (2003). Personal goals, life meaning, and virtue: Wellsprings of a positive life. I Dans Keyes, C.L.M. \& Haidt, J. (Eds.) Flourishing. Positive psychology and the life welllived (pp.105-128). Washington: American Psychological Association.

Freeman, A. \& Reinecke, M.A. (1993). Cognitive therapy of suicidal behavior. A manual for treatment. New York : Springer.

Hawton, K. et al. (1998). Deliberate self-harm: Systematic review of efficacy of psychosocial and pharmacological treatments in preventing repetition. British Medical Journal, 317, 441-447.

Hepp, U., Wittmann, L., Schnyder, U., \& Michel, K. (2004). Psychological and psychosocial interventions after attempted suicide. An overview of treatment studies. Crisis, 25(3), 108-117.

Lapierre, S., \& Bouffard, L. (2001a). Évaluation du vécu à la retraite [Retirement Experience Assessment Scale]. Upublisert manuskript, Université du Québec à Trois-Rivières. 
(Lapierre et al.: Ref. forts. fra s. 26.)

Malone, K.M., Oquendo, M.A., Haas, G.L., Ellis, S.P., Li, S., \& Mann, J.J. (2000). Protective factorsagainst suicidal acts in major depression: Reasons for living. American Journal of Psychiatry, 157(7), 1084-1088.

Michel, K. \& Valach, L. (2001). Suicide as goaldirected action. In K. van Heeringen (Ed.),

Understanding suicidal behavior (s. 230-254).

New York: John Wiley .

Préville, M., Potvin, L., \& Boyer, R. (1995). The

structure of psychological distress. Psychological

Reports, 77, 275-293.

Roberts. K.T. \& Aspy, C.B. (1993). Development

of the Serenity scale. Journal of Nursing Measurement, 1(2), 145-164.

Rothermund, K. \& Brandtstädter, J. (2003).

Depression in later life: Cross-sequential patterns and possible determinants. Psychology and Aging, 18(1), 80-90.

Schmuck, P., \& Sheldon, K.M.(Eds.) (2001).

Life Goals and Well-Being: Toward a Positive Psychology of Human Striving. Seattle: Hogrefe \& Huber Publishers.

Snyder, C.R. \& Rand, K. (2004). Hopelessness and health. I N. Anderson (Ed.), Encyclopedia of health and behaviour-Vol. 2 (s. 521-523).

Thousands Oaks, CA : Sage.

Snyder, C. R., Sympson, S. C., Ybasco, F. C., Borders, T. F. Babyak, M. A, \& Higgins, R. L. (1996). Development and validation of the state hope scale. J. Pers. Soc. Psy., 70 (2), 321-335.

Stones, M. J., Kozma, A., Hirdes, J., Gold, D., Arbukle, T., \& Kolopack, P. (1996). Short happiness and affect protocol (SHARP). Social Indicators Research, 34, 75-91.

Watson, D. L., \& Tharp, R. G. (1997). Selfdirected behavior. Pacific Grove, CA:

Brooks/Cole.

Yesavage, J.A., Brink, T.L., Rose, T.L., Lum, O., Huang, V., Adey, M., Leirer, V.O. (1983). Development and validation of a geriatric depression screening scale: A preliminary report. Journal of Psychiatric Research, 17(1), 37-49. 